This item was submitted to Loughborough's Research Repository by the author.

Items in Figshare are protected by copyright, with all rights reserved, unless otherwise indicated.

\title{
Investigating and preventing ankle sprain
}

PLEASE CITE THE PUBLISHED VERSION

http://dx.doi.org/10.1142/9781786340429_0004

\section{PUBLISHER}

(c) World Scientific Publishing Company

\section{VERSION}

AM (Accepted Manuscript)

\section{PUBLISHER STATEMENT}

This work is made available according to the conditions of the Creative Commons Attribution-NonCommercialNoDerivatives 4.0 International (CC BY-NC-ND 4.0) licence. Full details of this licence are available at: https://creativecommons.org/licenses/by-nc-nd/4.0/

\section{LICENCE}

CC BY-NC-ND 4.0

\section{REPOSITORY RECORD}

Fong, Daniel Tik-Pui. 2019. "Investigating and Preventing Ankle Sprain". figshare. https://hdl.handle.net/2134/25253. 


\section{Chapter 4}

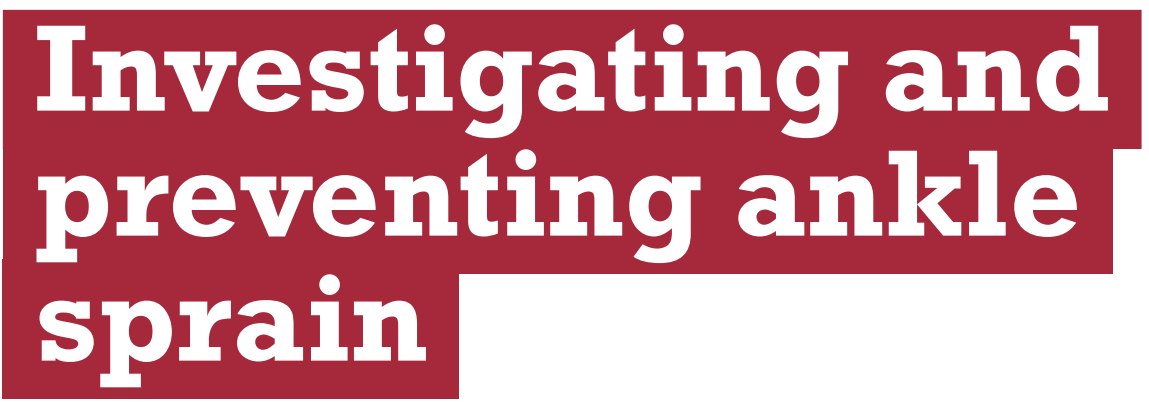

Dr Daniel Tik-Pui Fong

Loughborough University

A

nkle sprain injury is very common in sports. Without proper care, an ankle sprained for five or more times can be more prone to chronic ankle instability. In severe condition, it may lead to articular cartilage defect, early joint osteoarthritis

and deformity, which may ultimately need surgical treatment to reconstruct, or to replace with an artificial joint. Besides research on the treatment and rehabilitation, it is also worth conducting research on its prevention. Sports biomechanists can contribute in injury prevention, by analysing injury aetiology and mechanism, designing preventive intervention, and evaluating the effectiveness in a biomechanics laboratory [1]. Since 2004, I and my research team in the Sport Performance and Biomechanics Laboratory at Department of Orthopaedics and Traumatology, The Chinese University of Hong Kong had been investigating and preventing sport-related ankle ligamentous sprain injury. 


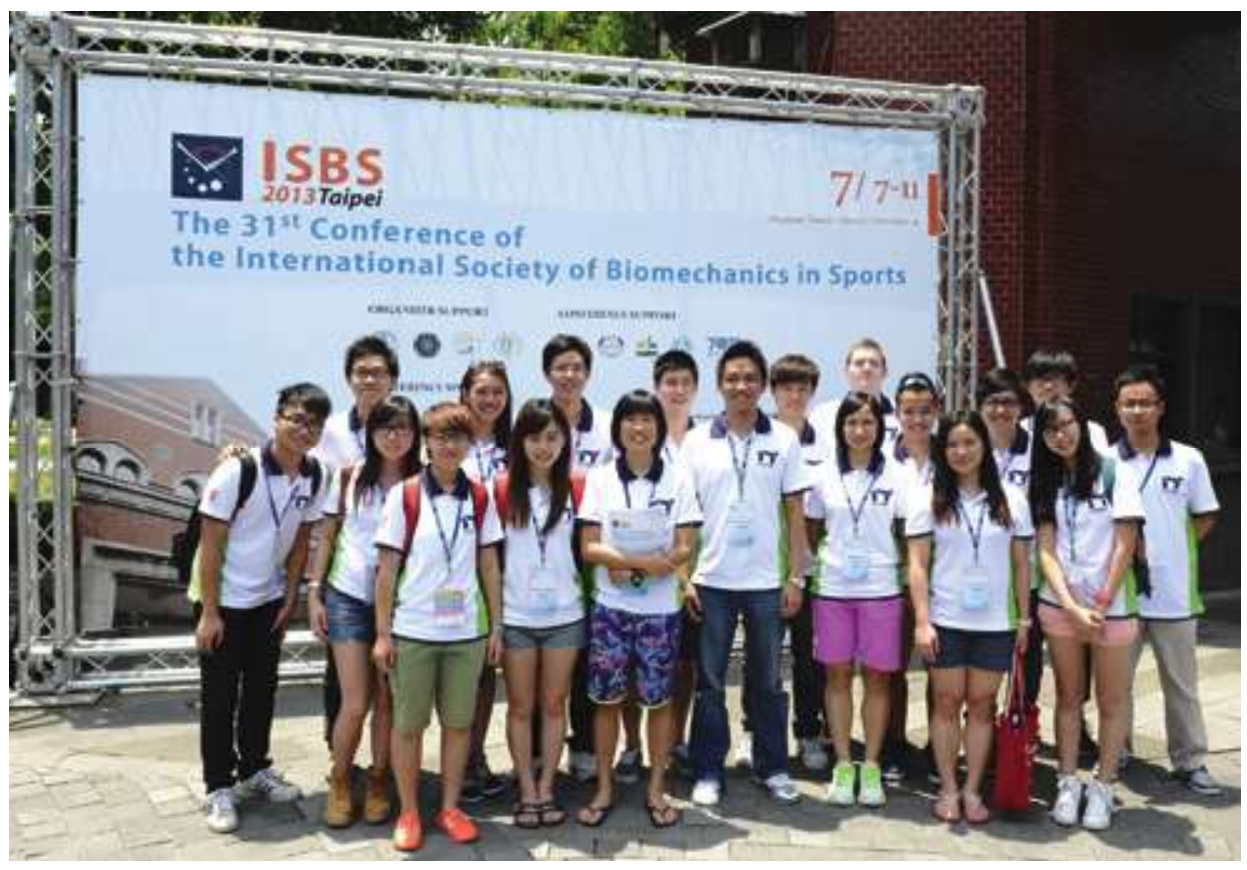

Figure 4.1: Dr Daniel Fong's Sport Performance and Biomechanics Research Team in 2013.

The first step was to understand the extent of the problem, and thus I conducted a systematic review which summarized 227 epidemiology studies since the first study published in 1977 [2]. It suggested that the ankle joint was the second common injured body site in sports, with inversion sprain being the most common diagnosis accounting for $84 \%$, and the injury incidence was highest in rugby, football, volleyball, handball and basketball. Local studies reported that $81 \%$ of ankle sprain injuries attending an emergency centre were ligamentous sprains sustained mainly in basketball (37\%) and football (29\%) sports [3], and only one-sixth of the patients injured athletes chose to attend an emergency centre, consult orthopaedic specialists, or seek physiotherapy treatment. Therefore the total number of sports injuries could be estimated the greatest among all kinds of injuries. Although we now have "better" sports shoes and protective gear, the prevalence and incidence of ankle sprain is still comparable to the previous 36 years.

While it is important to know the pattern of the injury, it is essential to know the cause and the process of the injury. For the cause, or the aetiologies, we summarized the knowledge from the literature and elaborate it in two aspects [4]. Firstly, an incorrect landing posture with a slightly inverted or supinated ankle joint causes a ground reaction force acting on the lateral foot edge to point medially and not pass through the ankle joint centre, thus creating a vigorous inward twisting torque, subsequent excessive inversion, and finally high ligament strains which tear the lateral ligaments (Figure 4.2). Secondly, the reaction of the peroneal muscles, which function to resist ankle inversion, is too slow $(60-90 \mathrm{~ms})$ to catch up to accommodate the sudden explosive inversion which happened within $50 \mathrm{~ms}$ after a foot strike. The stability of a joint depends on both the contraction of the muscles and the contribution from the ligaments, therefore, when the muscles are inactive, the joint stability would rely mainly on the ligaments. Since the ligaments possess viscoelastic property, a sudden explosive stretch would tear them. 


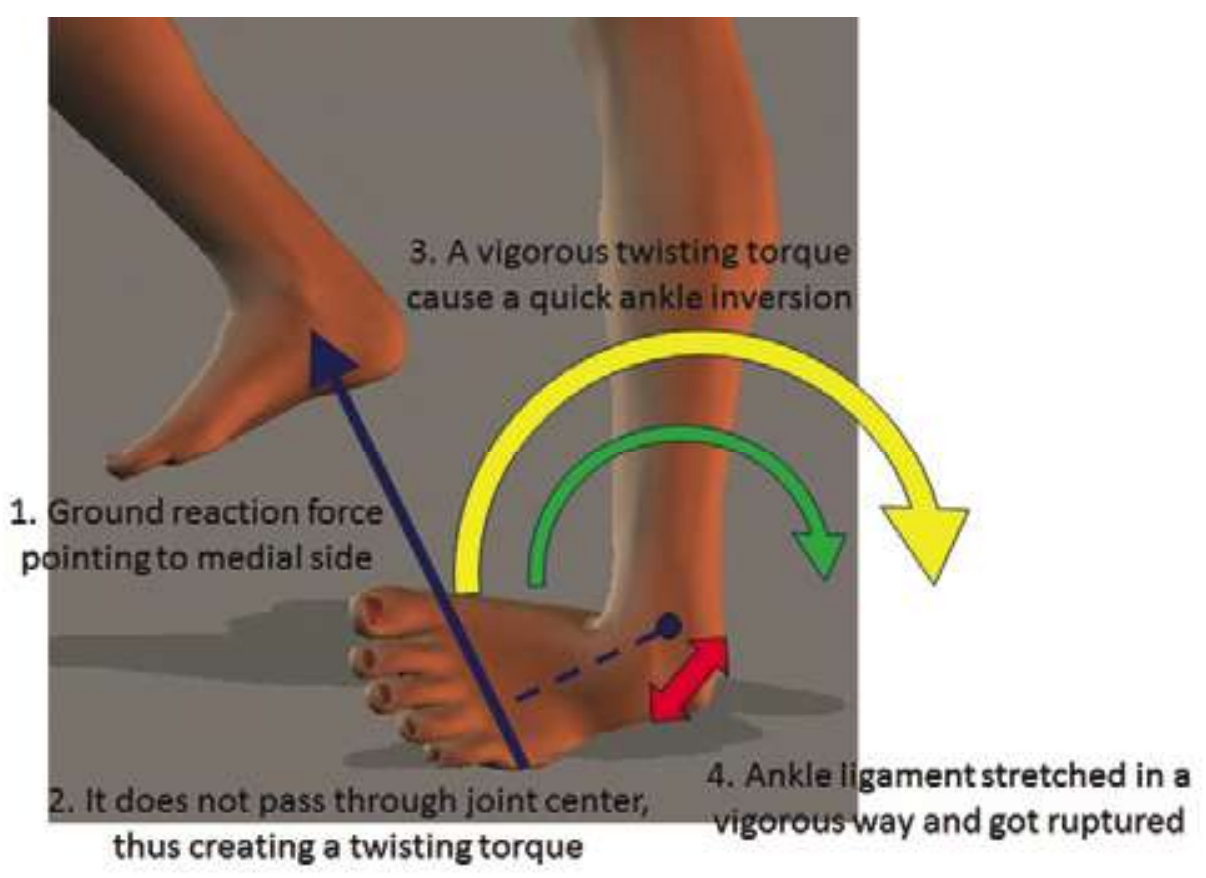

Figure 4.2: A graphical illustration of one of the causes of ankle inversion sprain injury.

The clinically presented mechanism which was an excessive supination, a combination of inversion and plantarflexion motion at the ankle joint, was not adequate for forensic biomechanists and biomedical engineers to analyze and prevent the injury. Over the past 10 years, I was fortunate enough to capture one accidental ankle sprain case during a sports shoe stability test in a laboratory (Figure 4.3). The injury was immediately diagnosed by an orthopaedic specialist to be a grade I anterior talofibular ligament sprain injury, and I presented the injurious motion with biomechanics quantities - this was the first ever ankle sprain biomechanics case report [5]. After this, to date, there were two more similar reported cases from Oslo [6] and Freiburg [7]. However, it is impractical to rely on such injury incidents captured unintentionally for a systematic study, as it may take a very long time or forever to obtain a significant amount of cases.
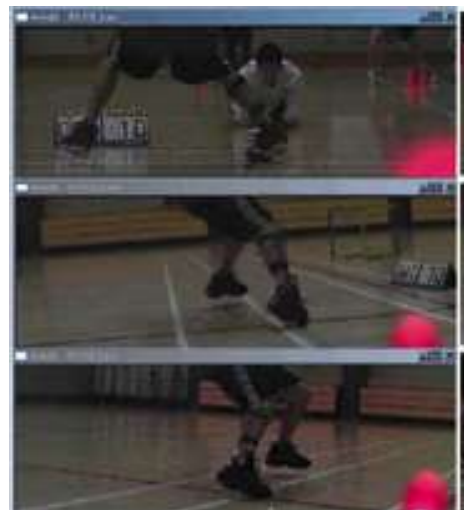

Figure 4.3: An accidental ankle sp
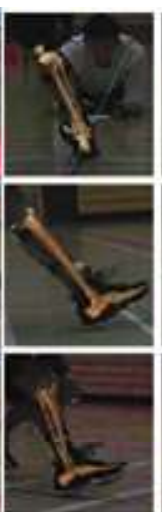
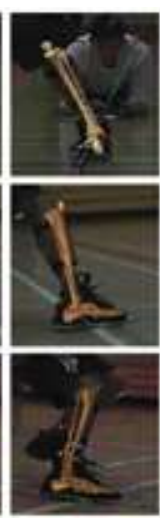
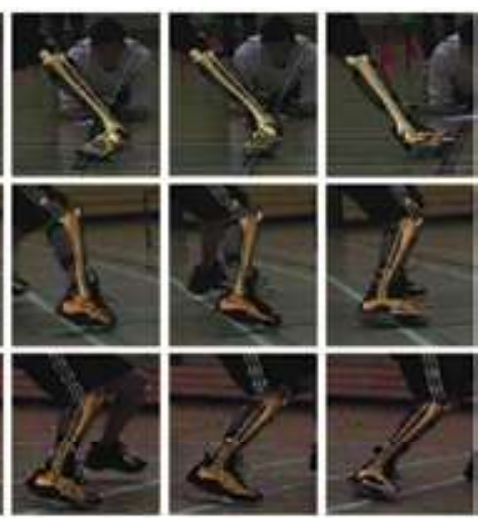

in a laboratory. 
In order to quantitatively analyze the injury mechanism, I collaborated with Oslo Sports Trauma Research Centre and developed a model-based image-matching motion analysis technique for the purpose [8], and utilized it to study real injury cases captured in televised sports events $[9,10]$. The data from these reports suggested that the ankle joints were all in an inverted and internally rotated orientation, plus either a dorsiflexed or plantarflexed ankle orientation (Figure 4.4). Nevertheless, all data showed high inversion velocities $(>500 \mathrm{deg} / \mathrm{s})$ which were all greater than that collected during common sporting activities [11]. I further used the profile of ankle kinematics data to drive a computational foot and ankle model (Figure 4.5) developed by Michigan State University and Northwestern University to simulate the injury [12], and the result suggested that an inversion moment of $23 \mathrm{Nm}$ and an internal rotation moment of $11 \mathrm{Nm}$ were presented, resulting in a $15-20 \%$ strain at the anterior talofibular ligament [13].

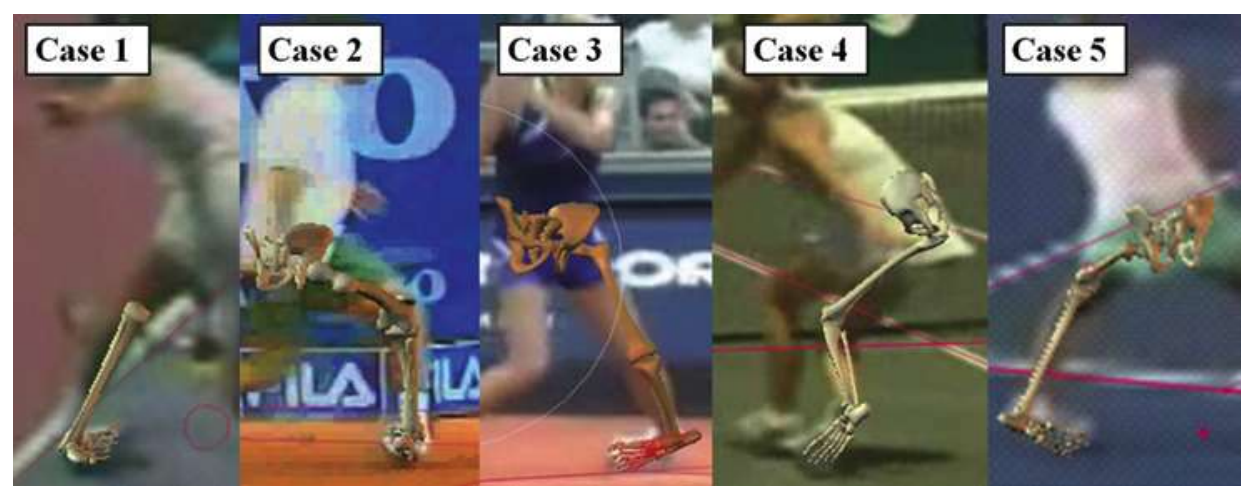

Figure 4.4: Screenshots of five ankle sprain injury cases in tennis competitions. All ankles were inverted and internally rotated, plus either a dorsiflexed or plantarflexed orientation.

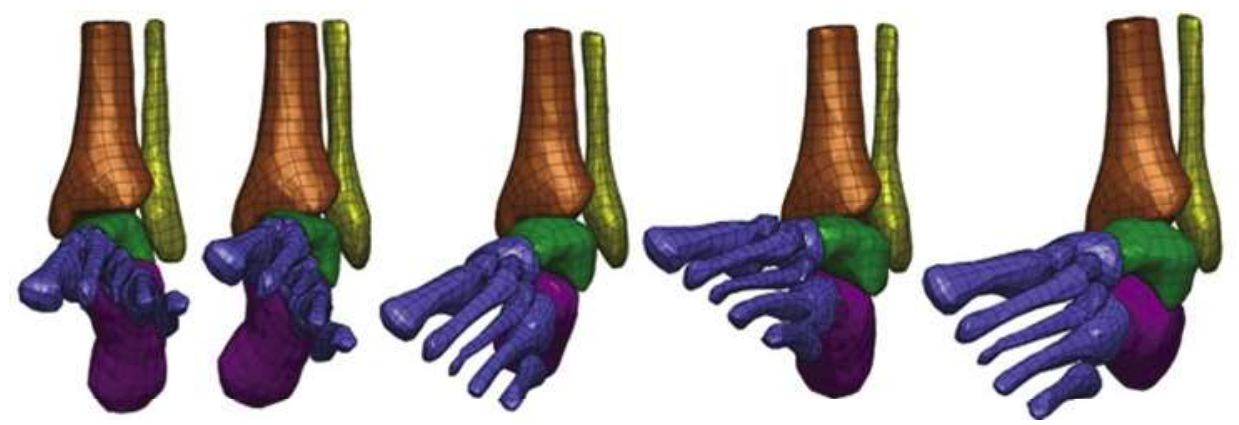

Figure 4.5: A computational foot and ankle model to simulate the injury incident to determine the joint torque and ligament strain.

The above-mentioned studies had provided some knowledge for the understanding of the ankle inversion sprain injury. Then my research team proceeded with the prevention of the injury. We started with shoes [14], as I believed that the design of the construct of shoes or inserts may change the foot and ankle biomechanics, 
hopefully in a desired way $[15,16,17]$. Based on the two identified aetiologies, a monitor system was designed to detect incorrect landing posture, and a corrective system was designed to overcome the delayed peroneal muscle reaction.

For the monitor system, the first attempt was to monitor the ankle joint supination torque. In a biomechanics laboratory, such is often determined by inverse dynamic calculation with kinematics, kinetics and anthropometry data. I first devised a method to estimate complete ground reaction force from pressure insoles [18], and further calculated the ankle joint supination torque [19]. Although we reported that a $23 \mathrm{~N}$ m inversion moment was observed during an ankle sprain injury, there was a need to determine the threshold which the ligament started to tear. For this purpose, a cadaveric biomechanics study was conducted [20], but the attempt was suspended after all because the twisting speed on the cadaveric specimen had not been concerned, and the device utilizing pressure sensors for estimation would record no data when a foot rolls over the lateral edge to sustain an ankle sprain injury. The second attempt was to use motion sensors to identify injury-like and normal motion. For this purpose, a mechanical sprain simulator was built [21], and a total of 300 injury-like and 300 normal motions were collected by eight motion sensors attached to the dorsal foot. A support vector machine model was used to identify these motions, and the method reached an accuracy of $91.3 \%$ [22]. However, the method was also suspended as the identification could only be done post data collection, but not in a real-time manner. The final attempt was to use a uni-axial gyrometer attached to the heel counter (Figure 4.6) and to identify the injury hazard by the inversion velocity [23]. The threshold was based on the data from the reported injury incidents and the normal motions we collected.
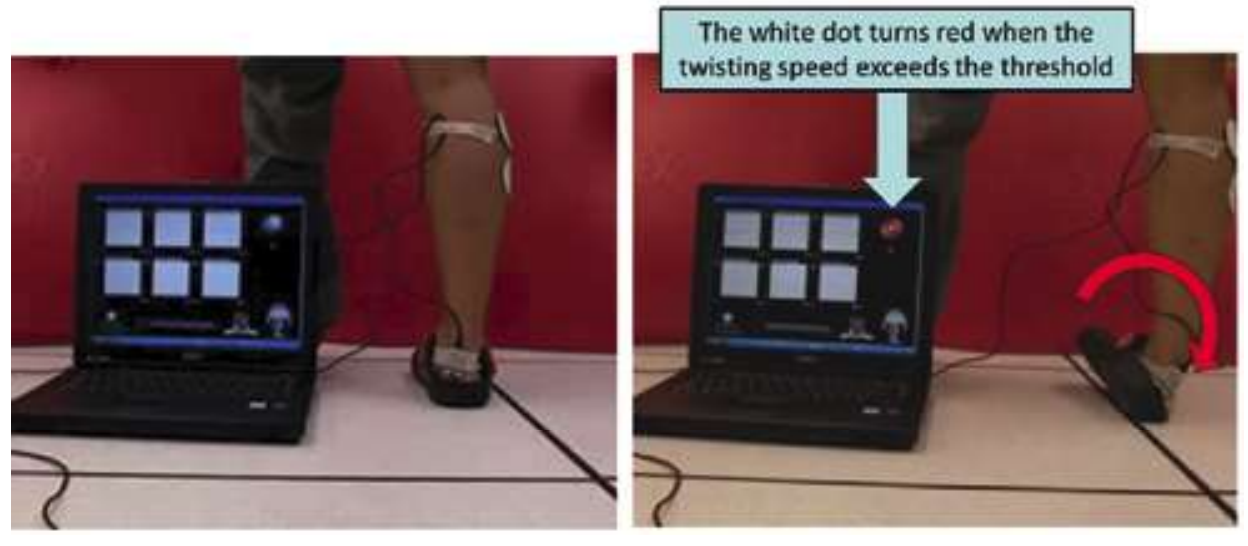

Figure 4.6: An uni-axial gyrometer is attached to the heel counter to identify the injury hazard by the twisting velocity.

For the corrective system, the first attempt was to design a semi-rigid brace with magnetorheological fluid which turns rigid in a very short time when a magnetic field is present - this was done by closing the circuit of an electric coil in our device. However the attempt was suspended as the material cost was high, and we were not sure if there is any potential health hazard in case of leakage of the metal fluid. The current attempt is to deliver myoelectric stimulation to the peroneal muscles (Figure 4.7) to initiate very fast ankle eversion or pronation within $25 \mathrm{~ms}$ 
to resist the injury mechanism which happens within $50 \mathrm{~ms}$ after the foot strike [24]. The system has been evaluated to be effective in a biomechanics laboratory, and was granted US patent in 2012 [25] and Chinese patent in 2013. Because of the position of the peroneal muscle belly, the stimulation has to be delivered at the upper shank for the best effect [26], and the system is currently carried by a pair of wireless wearable parts, or a sport legging covering the whole shank. The device only gives mechanical support by assisting the muscle reaction to generate muscular forces when in need, and allows the athlete to have an agile ankle joint for most of the time for the best performance.

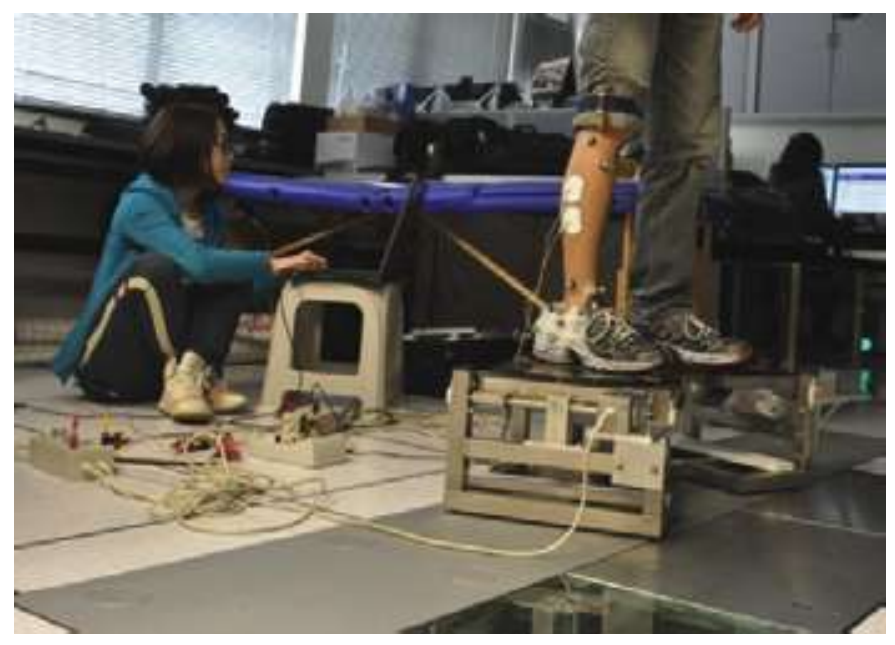

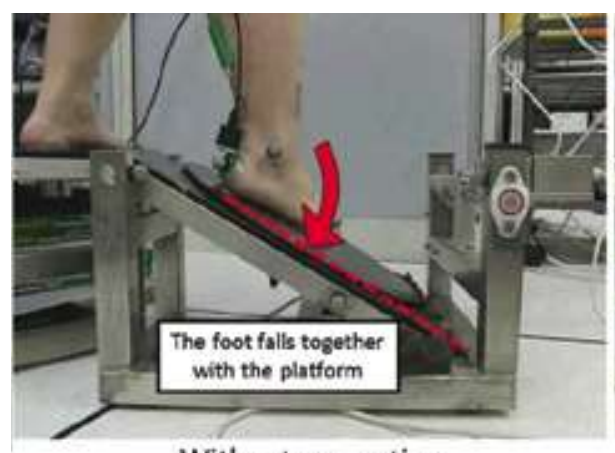

Without correction

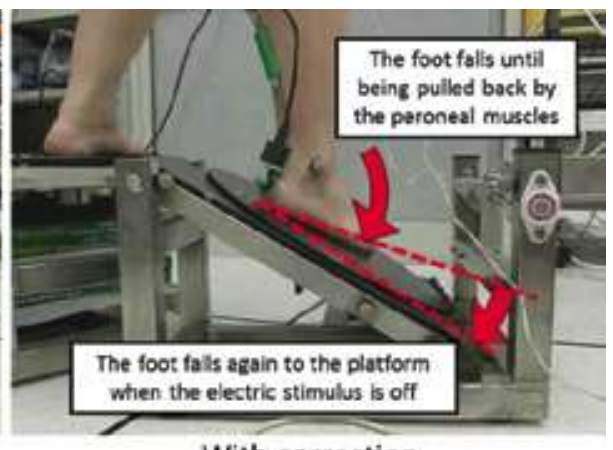

With correction

Figure 4.7: Electrical stimulation is given to the muscles at the lateral shank for stopping the ankle sprain injury motion.

The intelligent anti-sprain system is being revised for better accuracy in identifying injury risk, and for better agility, comfort, durability and user setting interface when it is being carried in a pair of sport legging (Figure 4.8). We are still conducting some refinement research work to improve the accuracy in identifying the injurious hazardous motion, the optimization of the electrical stimulation to provide the best prevention effect and comfort, and to include advanced textiles technology to improve the quality of the final wearable apparel. The invention will be commercialized as a prophylactic sport apparel in the coming years. 


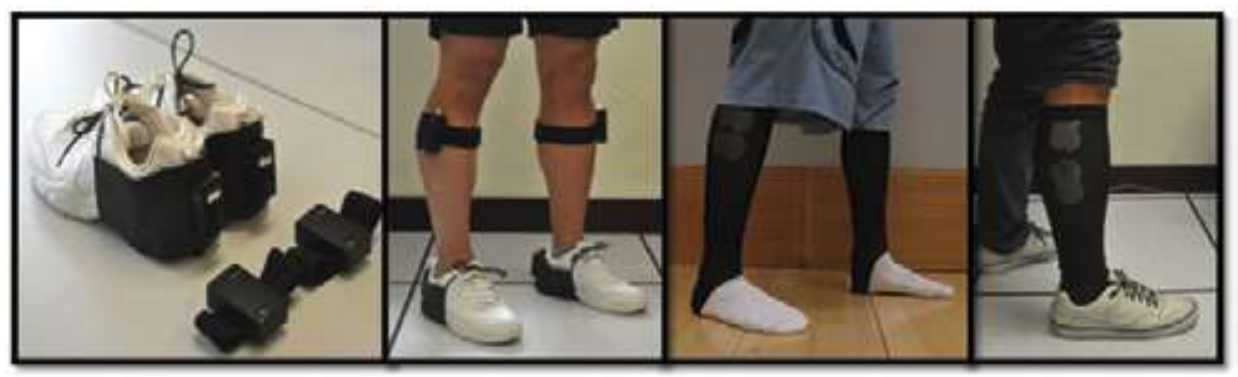

Figure 4.8: The first prototype as two pairs of detachable parts at the heel counter and the shank, and the second prototype as a pair of sport legging.

\section{REFERENCES}

1. Chan, K.M., Fong, D.T.P., Hong, Y., Yung, P.S.H., \& Lui, P.P.Y. (2008). Orthopaedic sport biomechanics - a new paradigm. Clinical Biomechanics, 23(1 Supp), S21-30.

2. Fong, D.T.P., Hong, Y., Chan, L.K., Yung, P.S.H., \& Chan, K.M. (2007). A systematic review on ankle injury and ankle sprain in sports. Sports Medicine, 37(1), 73.94.

3. Fong, D.T.P., Man, C.Y., Yung, P.S.H., Cheung, S.Y., \& Chan, K.M. (2008). Sport-related ankle injuries attending an accident and emergency department. Injury, 39(10), 1222-1227.

4. Fong, D.T.P., Chan, Y.Y., Mok, K.M., Yung, P.S.H., \& Chan, K.M. (2009a). Understanding acute ankle ligamentous sprain injury in sports. Sports Medicine, Arthroscopy, Rehabilitation, Therapy and Technology, 1, 14.

5. Fong, D.T.P., Hong, Y., Yung, P.S.H., Shima, Y., Krosshaug, T., \& Chan, K.M. (2009b). Biomechanics of supination ankle sprain - a case report of an accidental injury event in laboratory. American Journal of Sports Medicine, 37(4), 822-827.

6. Kristianslund, E., Bahr, R., \& Krosshaug, T. (2011). Kinematics and kinetics of an accidental lateral ankle sprain. Journal of Biomechanics, 44(14), 2576-2578.

7. Gehring, D., Wissler, S., Mornieux, G., \& Gollhofer, A. (2013). How to sprain your ankle - a biomechanical case report of an inversion trauma. Journal of Biomechanics, 46(1), 175-178.

8. Mok, K.M., Fong, D.T.P., Krosshaug, T., Hung, A.S.L., Yung, P.S.H., \& Chan, K.M. (2011b). An ankle joint modelbased image-matching motion analysis technique. Gait and Posture, 34(1), 71-75.

9. Mok, K.M., Fong, D.T.P., Krosshaug, T., Engebretsen, L., Hung, A.S.L., Yung, P.S.H., \& Chan, K.M. (2011a). Kinematics analysis of ankle inversion ligamentous sprain injuries in sports - two cases during the 2008 Beijing Olympics. American Journal of Sports Medicine, 39(7), 1548-1552.

10. Fong, D.T.P., Ha, S.C.W., Mok, K.M., Chan, C.W.L., \& Chan, K.M. (2012c). Kinematics analysis of ankle inversion ligamentous sprain injuries in sports - five cases from televised tennis competitions. American Journal of Sports Medicine, 40(11), 2627-2632.

11. Chu, V.W.S., Fong, D.T.P., Chan, Y.Y., Yung, P.S.H., Fung, K.Y., \& Chan, K.M. (2010). Differentiation of ankle sprain motion and common sporting motion by ankle inversion velocity. Journal of Biomechanics, 43(10), 2035-2038

12. Fong, D.T.P., \& Wei, F. (2012). The use of model matching video analysis and computational simulation to study ankle sprain injury mechanism. International Journal of Advanced Robotic Systems, 9, 97.

13. Wei, F., Fong, D.T.P., Chan, K.M., \& Haut, R. (in press). Estimation of ligament strains and joint moments in the ankle during a supination sprain injury. Computer Methods in Biomechanics and Biomedical Engineering. doi:10.1080/ 10255842.2013 .792809

14. Fong, D.T.P. (2012). An intelligent sport shoe to prevent ankle inversion sprain injury. Journal of Foot and Ankle Research, 5(Supp 1), K6. 
15. Fong, D.T.P., Lam, M.H., Lao, M.L.M., Chan, C.W.N., Yung, P.S.H., Fung, K.Y., Lui, P.P.Y., \& Chan, K.M. $(2008 \mathrm{c})$. Effect of medial arch-heel support in inserts on reducing ankle eversion: a biomechanics study. Journal of Orthopaedic Surgery and Research, 3, 7.

16. Fong, D.T.P., Hong, Y., \& Li, J.X. (2007). Cushioning and lateral stability functions of cloth sport shoe. Sports Biomechanics, 6(3), 407-417.

17. Fong, D.T.P., Pang, K.Y., Chung, M.M.L., Hung, A.S.L., \& Chan, K.M. (2012). Evaluation of combined prescription of rocker sole shoes and custom-made foot orthoses for the treatment of plantar fasciitis. Clinical Biomechanics, 27(10), 1072-1077.

18. Fong, D.T.P., Chan, Y.Y., Hong, Y., Yung, P.S.H., Fung, K.Y., \& Chan, K.M. (2008a). Estimating the complete ground reaction force with pressure insoles in walking. Journal of Biomechanics, 41(11), 2597-2601.

19. Fong, D.T.P., Chan, Y.Y., Hong, Y., Yung, P.S.H., Fung, K.Y., \& Chan, K.M. (2008b). A three-pressure-sensor (3PS) system for monitoring ankle supination torque during sport motions. Journal of Biomechanics, 41(11), 2562-2566.

20. Fong, D.T.P., Chung, M.M.L., Chan, Y.Y., \& Chan, K.M. (2012b). A mechanical jig for measuring ankle supination and pronation torque in vitro and in vivo. Medical Engineering and Physics, 34(6), 791-794.

21. Chan, Y.Y., Fong, D.T.P., Yung, P.S.H., Fung, K.Y., \& Chan, K.M. (2008). A mechanical supination sprain simulator for studying ankle supination sprain kinematics. Journal of Biomechanics, 41(11), 2571-2574.

22. Chan, Y.Y., Fong, D.T.P., Chung, M.M.L., Li, W.J., Liao, W.H., Yung, P.S.H., \& Chan, K.M. (2010). Identification of ankle sprain motion from common sporting activities by dorsal foot kinematics data. Journal of Biomechanics, 43(10), 1965-1969.

23. Fong, D.T.P., \& Chan, Y.Y. (2010). The use of wearable inertial motion sensors in human lower limb biomechanics studies - a systematic review. Sensors, 10(12), 11556-11565.

24. Fong, D.T.P., Chu, V.W.S., \& Chan, K.M. (2012a). Myoelectric stimulation on peroneal muscles resists simulated ankle sprain motion. Journal of Biomechanics, 45(11), 2055-2057.

25. Chan, K.M., Fong, D.T.P., \& Yung, P.S.H. (2012). Methods and devices for preventing ankle sprain injuries. U.S Patent No. 8,301,258. Washington, DC: U.S. Patent and Trademark Office.

26. Fong, D.T.P., Wang, D., Chu, V.W.S., \& Chan. K.M. (2013). Myoelectric stimulation on peroneal muscles with electrodes of the muscle belly size attached to the upper shank gives the best effect in resisting simulated ankle sprain motion. Journal of Biomechanics, 46(6), 1088-1091. 